\title{
Reconocimiento social en el marco del posconflicto en Colombia: el caso de las zonas de reserva campesina ${ }^{1}$
} Social Recognition in the Context of Colombia's Post-conflict: Case Study of Peasant Reserve Zones

\author{
Karen Natalia Fajardo-Herrera ${ }^{1}$, Amanda Vargas-Prieto $^{2} \bowtie$ \\ ${ }^{1}$ Profesional en Comercio Internacional, Universidad de La Salle, Colombia. \\ 2 Doctora en Ciencias Económicas, profesora asociada de la Universidad \\ de La Salle, Facultad de Ciencias Económicas y Sociales, Colombia.
}

Correo electrónico: amvargas@unisalle.edu.co

Recibido: 3 de agosto del 2017 Aprobado: 15 de diciembre del 2017 Disponible en línea:

Cómo citar este artículo: Fajardo-Herrera, K. N., Vargas-Prieto, A. (2018). Reconocimiento social en el marco del posconflicto en Colombia: el caso de las zonas de reserva campesina. Cooperativismo \& Desarrollo, 113(26). doi: https://doi. org/10.16925/co.v26i113.2189

\section{Resumen}

Propósito: este trabajo de reflexión se enfoca en dilucidar cómo las zonas de reserva campesina (ZRC) se pueden considerar una estrategia de reconocimiento social.

Temas: son varios los aspectos a tratar a través de este recorrido, entre estos resaltan nociones como la justicia, el reconocimiento y, principalmente, la identidad campesina colombiana.

Desarrollo: se ha evidenciado que las zRc han generado un impacto positivo en la medida en la que han permitido el restablecimiento de la identidad del campesinado en las zonas donde se han establecido, de modo tal que fortalecen las comunidades y las hacen partícipes de las decisiones en el ámbito social, en el económico y en el ambiental, entre otros.

Conclusiones: el territorio ha jugado un papel primordial en el desarrollo de las labores agrícolas, propias del modo de vida y de la idiosincrasia del campesino colombiano, por tanto, la figura de las ZRC tiene que ver con su reconocimiento social tanto a nivel poblacional como cultural y, por ende, su trascendencia histórica ha repercutido en el presente.

Palabras clave: campesinos, participación, reconocimiento social, zonas de reserva campesina (ZRC).

1 Artículo elaborado a partir de la investigación "Las zonas de reserva campesina como estrategia de reconocimiento social", con el cual se optó al título de profesional en Finanzas y Comercio Internacional bajo la asesoría de la profesora Amanda Vargas. 


\title{
Social Recognition in the Context of Colombia's Post-conflict: Case Study of Peasant Reserve Zones
}

\begin{abstract}
Purpose: The present reflection paper focuses on clarifying how peasant reserve zones (zcr from their initials in Spanish) may be considered a social recognition strategy.

Themes: Several aspects must be dealt with through this journey, among them are notions such as justice, recognition and, mainly, Colombian peasant identity.

Development: There is evidence that $\mathrm{ZCR}$ trigger a positive impact on the extent to which they allow peasant's identity restoration where they establish; this strengthens communities and lets them, take part of, among others, social, economic and environmental decisions.

Conclusions: Territory has played a major role in the development of farming and its correspondence with lifestyles and idiosyncrasies of Colombian peasants. This is why the zCR figure involves a social recognition both in cultural and population terms, as well as of their historical significance, which has had an impact on the present.
\end{abstract}

Keywords: peasants, participation, social recognition, peasant reserve zones (zCR).

\section{Reconhecimento social no contexto do pós-conflito na Colômbia: o caso das áreas de reserva camponesa}

\section{Resumo}

Objetivo: este trabalho de reflexão tem o objetivo de elucidar como as áreas de reserva camponesa (ARC) podem ser consideradas uma estratégia de reconhecimento social.

Questões: entre os diversos aspectos que serão tratados, destacam noções como a justiça, o reconhecimento e, principalmente, a identidade camponesa colombiana.

Desenvolvimento: foi demonstrado que as ARC geram um impacto positivo, dado que permitem restabelecer a identidade do campesinato nas áreas onde estão instalados, de forma que fortalecem as comunidades e tornam-nas parte das decisões nas esferas social, econômica, ambiental, entre outras.

Conclusões: 0 território tem desempenhado um papel fundamental no desenvolvimento do trabalho agrícola, típico do modo de vida e da idiossincrasia do camponês colombiano. Portanto, a figura das ARC está relacionada com o seu reconhecimento social a nível populacional e cultural e, por isso, sua transcendência histórica teve um impacto sobre o presente.

Palavras-chave: camponeses, participação, reconhecimento social, áreas de reserva de camponesa (ARC). 


\section{Introducción}

Colombia atravesó un proceso de violencia que se extendió por más de medio siglo. Esto, no solo ligado a la presencia y la conformación de grupos al margen de la ley, sino también como consecuencia de una guerra entre los mismos partidos políticos que ha generado el desplazamiento interno de la población, con cifras que en la actualidad han hecho que Colombia sea el país con el mayor índice de desplazamiento en el mundo, incluso por encima de Siria (ACNUR, 2016).

Así, desde 1997 hasta el 2013, se registró el desplazamiento de 5185406 personas en Colombia. En el 2007, el 25\% de las cifras de desplazados se concentraba en 17 municipios, porcentaje que se incrementó para el 2013, momento en el cual el $50 \%$ de los desplazados provenían de 10 municipios: Buenaventura, Medellín, Tierralta, Suárez, Ricaurte, Riosucio, López de Micay y Puerto Asís. Dichas localidades se concentran en su mayoría en los departamentos de Antioquia, Nariño y Chocó. Este desplazamiento perjudicó alrededor de 6881 familias, quienes provienen principalmente de las zonas rurales (ACNUR, 2015).

La población víctima de desplazamiento reclama del Estado colombiano la redistribución de sus tierras, la recuperación de sus viviendas y la protección del territorio. Con este propósito se crearon las denominadas "zonas de reserva campesina" (ZRC) por medio de la Ley 160 de 1994. De esta manera, se conforma una nueva figura del proceso de ordenamiento territorial que tiene como objetivo delimitar la frontera agrícola, reducir la problemática de concentración de tierras, crear condiciones para la consolidación y el desarrollo sustentable de la economía campesina y regular la ocupación de los terrenos baldíos (al darles preferencia, primordialmente, a los campesinos con escasos recursos), todo esto mediante la conformación de políticas integrales enfocadas en el desarrollo rural.

Las Zonas de Reserva Campesina se definen como "las áreas geográficas que son escogidas por la Junta Directiva del Instituto Colombiano de la Reforma Agraria (Incora), para lo cual contemplan las características agroecológicas y socioeconómicas regionales" (Ley 160 de 1994). Asimismo, en el Decreto 1777 de 1996 se determina el objetivo de la conformación de las ZRC, adjudicándosele la meta de "fomentar y estabilizar la economía campesina, superar las causas de los conflictos sociales que las afectan y de manera general, crear las condiciones para alcanzar la paz y la justicia social en las áreas respectivas" (Decreto 1777 de 1996, artículo 1).

El Gobierno colombiano, a partir de la Ley de Victimas y Restitución de Tierras de 2011 buscó abordar la problemática del desplazamiento forzado, a la vez que reasignó recursos financieros para darle soporte. En el 2013 se registró un hecho significativo por parte de la Corte Constitucional, órgano que reglamentó cómo las víctimas de los grupos que se desmovilizaron deberían ser beneficiadas desde los parámetros de cuidado, atención y reparación, esto en función de lo dispuesto en la Ley 1448 del 2011 y en concordancia con la ampliación del concepto de víctima que se describe en el artículo 3 de la ley en mención.

Se creó una serie de modificaciones de las condiciones jurídicas por medio del Código de Minas. Bajo esta normativa también se establece que uno de los objetivos de las ZRC se relaciona con el control de la frontera agropecuaria, la delimitación de la problemática de la concentración de la tierra por parte de los grandes terratenientes, la conformación de alternativas que garanticen el desarrollo sostenible de la economía campesina, el acceso de los campesinos a las tierras baldías, el impulso de políticas direccionadas al desarrollo rural y el fortalecimiento del reconocimiento social entre el Estado colombiano y las comunidades rurales.

Como complemento a la legislación anterior, por medio del Acuerdo 026 del 2009, más que definir criterios respecto a las ZRC se conforman y establecen objetivos que se orientan a la superación y mitigación de los causantes de los conflictos de orden social mediante el impulso de la preservación del orden público y los programas de sustitución de cultivos ilícitos. De igual forma, se aborda la protección y la conservación del medio ambiente, para lo cual se cuenta con el apoyo del Sistema Nacional de Reforma Agraria y Desarrollo Rural Campesino, de entes como el Sistema Nacional Ambiental y de otros organismos de carácter público y privado que tienen como función formular, financiar y llevar a cabo los planes de desarrollo sostenible, las investigaciones, los programas y los proyectos para las zonas de reserva campesina.

En Colombia se invisibilizó la figura del campesino desde la propia Constitución Política de 1991, en la que se excluyó como sujeto activo de la sociedad con derecho a tener una identidad propia, al punto de invisibilizar sus derechos y de rezagar 
así uno de los actores principales del país. El campesino colombiano ha sido objeto de desigualdad, exclusión y maltrato por parte del Estado, el cual lo ha mantenido indudablemente en la sombra del olvido (Fajardo-Herrera, 2015). Ante esto, es indispensable generar soluciones a la problemática desde un ámbito social, económico, social, cultural y político con la garantía de un enfoque de desarrollo humano integral y sustentable (Rural, 2007). Así, entonces, en el siguiente apartado se discute sobre si las zonas de reserva campesina se pueden considerar como una estrategia de reconocimiento social de los campesinos en el marco del posconflicto. ${ }^{2}$

\section{La necesidad de reconocimiento del campesinado en la búsqueda de la reducción de la desigualdad}

La igualdad es el principio de oportunidades que busca un punto de partida igual para todas las personas ante la ley y la sociedad. La igualdad se vulnera tanto en el momento en que, al tener que tratar como iguales a todos los miembros de una sociedad, se le da un trato diferente a uno de ellos por alguna causa no razonable o justificable, necesaria o idónea. En el caso de la población rural en Colombia, se presenta desigualdad desde la repartición de tierras hasta la producción y comercialización de productos del campesinado, lo cual no es equitativo debido a que las diferentes partes (el empresario y el campesinado) no tienen el mismo poder y los campesinos son la parte débil de la relación (Fuerte y Tacha, 2015). La lucha por la protección de los derechos humanos de la población campesina deben reconocerla todos los miembros de la sociedad. Esta situación radica en una cruel realidad en la que sus derechos no solo se vulneran, sino que ni siquiera se reconocen. Así, y si se empieza por la Constitución Política colombiana, se debe adoptar una "declaración sobre los derechos de los campesinos y de otras personas que trabajan en las zonas rurales" (Morales, 2015, p. 1), lo que permita generar desde las directrices constitucionales

\footnotetext{
2 Este artículo es el resultado de una investigación realizada en la Universidad de La Salle en la Facultad de Ciencias Económicas y Sociales entre el 2015 y el 2017. La metodología utilizada se basó en una triangulación de técnicas, entre las que se encuentran la revisión bibliográfica y las entrevistas a expertos. Las respectivas entrevistas y la información encontrada en los documentos se analizaron mediante el software Atlas.Ti, un programa especializado en el método cualitativo.
}

el inicio de un reconocimiento por el cual las comunidades campesinas han abogado por muchos años. Es importante resignificar el lenguaje a fin de estar en capacidad de comprender la realidad rural - que es histórica en Colombia-, sobre todo con el fin de estar en capacidad de transformarla mediante la reconstrucción de las condiciones que permitan seguir con el cultivo de la tierra. Lo anterior en razón a que el problema radica en la existencia de modos de vida que no han sido debidamente valorados, por lo cual las formas en las que se produce el saber de esas personas que decidieron vivir de manera distinta a la de la sociedad mayoritaria tampoco se valoran. En este sentido, esas personas tienen un saber que debe reconocerse y exaltarse, lo cual pasa necesariamente por buscar el significado de las palabras y la manera en la que se relacionan estas y las cosas.

En el propósito de definir el concepto de campesino se debe preguntarle a la gente que vive de otras maneras, a la gente que está en el campo y a la gente que se reivindica como tal: ¿cómo son?, ¿qué son? La academia debe ceder esa pretensión de querer definirlo solo desde su perspectiva y desde lo que cree entender, y más bien buscar la opción de que la gente hable, se exprese y manifieste lo que es, con el fin no tanto de plantear una definición, sino de recuperar el concepto del campesino como un sujeto histórico que ha jugado un papel importante en el país. Sin embargo, lejos de ser una población anclada en el pasado, los campesinos han desarrollado estrategias para afrontar las situaciones que viven cotidianamente. En este orden de ideas, han tenido que acoplarse a las dificultades que representa la guerra y, por tanto, sus condiciones han cambiado con el propósito de sobrevivir a las inclemencias que se les presentan. De esta manera, resulta una población muy dinámica y adaptativa a los cambios que les exigen los diferentes entornos políticos, sociales, culturales, económicos y ambientales, pues cambian incluso su forma de hacer agro y tratan de crear organizaciones y cooperativas. Pese a esto, los campesinos se han relegado numéricamente; hace unas décadas eran el $70 \%$ de la población, ahora son menos del $30 \%$. Cuantitativamente pueden ser menos de 15 millones de personas las que en Colombia se consideran campesinos (DANE, 2016).

En Colombia, hay quienes consideran que a los pobladores rurales que viven de la tierra se les conoce, desde la antigüedad, como campesinos y encuentran estrategias para seguir sobreviviendo 
como productores. También hay quienes consideran que en el país ya no se les reconoce como tal, dada la diversidad de usos que se les ha dado a las zonas rurales. Ante esto, surge la pregunta: ¿Quiénes son los campesinos colombianos en la actualidad? Para algunos es difícil generalizar, aun cuando se trata de una categoría que tiene una identidad vigente, $y$ a pesar de haber sido una población excluida y estigmatizada. Así, los campesinos colombianos son todavía un sector social, si bien excluido, con una privación de derechos políticos, económicos y sociales que se debe a un fallo de reconocimiento de derechos histórico. Ese fallo de reconocimientos se encuentra en toda la conflictividad de la última etapa de la historia colombiana: campesinos sin derechos, campesinos que se expropian, se despojan, se desplazan, un panorama que se presenta desde la década de los cuarenta y se caracteriza como una etapa de irresolución -que en la práctica es un problema de inclusión-, en la cual cualquier sector social que no se incluye termina en una tensión con el resto. Además, en un país tan desigual como Colombia, donde todo el poder político y económico siempre se ha concentrado en una élite, el campesino es un sujeto no reconocido que, paradójicamente, ha jugado un papel histórico en la etapa también de la modernidad colombiana. Esto en razón a que, a pesar de ser un país de campesinos, un país agrícola y agropecuario, a este sector se le mantiene en esa situación de privación hasta el momento en que se vislumbra la generación de un nuevo escenario incluyente para el campesinado, lo que significaría sin duda toda una transición en lo político y en lo económico, con las consecuentes repercusiones de índole social. Finalmente, para otros, los campesinos colombianos en la actualidad son los pocos ciudadanos que conservan sus tierras, las trabajan y se mantienen de lo que producen allí; asimismo, los millones que trabajan para otros en el cultivo de la tierra y muchos otros desplazados a las ciudades por el conflicto armado.

De acuerdo con el proyecto de la Ley General Agraria y de Desarrollo Rural, se afirma que las ZRC son un mecanismo de ordenamiento productivo del territorio rural que está orientado y dirigido a:

(i) Regular limitar y ordenar la propiedad, corregir y evitar su concentración o división antieconómica, o ambos, garantizar que el desarrollo de actividades de explotación observe preceptos ambientales que permitan su sostenibilidad (ii) diseñar e implementar concertadamente proyectos productivos sostenibles que consoliden y desarrollen la economía campesina, (iii) garantizar la presencia institucional en zonas que han expuesto a sus habitantes a condiciones de marginalidad con nula o baja presencia del Estado, (iv) garantizar la participación de las organizaciones representativas de los campesinos en las instancias de planificación y decisión regionales, así como la efectividad de sus derechos sociales, económicos y culturales. (Osejo, 2013, p.14).

Por medio de las ZRC la población campesina exige su reconocimiento por parte del Estado y de la sociedad, exige que los escuchen en sus territorios, piden un reconocimiento como actor político y proporcionan un reconocimiento más allá de lo ambiental, por el cual se plantee una pertenencia a la comunidad que sea incluyente tanto en el campo como en la ciudad.

Los campesinos colombianos son muy diversos en sus prácticas productivas y culturales, en sus características socioeconómicas y en sus formas de sentir y actuar en la vida en el campo. Es importante que las políticas públicas para el agro reconozcan esta diversidad y logren abarcar todas las problemáticas del campesinado. Bajo estos aspectos se podría desarrollar el principio de igualdad en el que el reconocimiento proporciona las bases para su implementación, tal como se presenta a continuación.

\section{La "justicia de reconocimiento" para identificar la identidad de los campesinos}

A finales del siglo xx Honneth (1997) presenta una teoría - basada en la tradición del idealismo alemán- sobre el reconocimiento de la dignidad de las personas como elemento central del concepto de justicia. Esto, para él, es un acrecentamiento de sensibilidad moral al transcender la reivindicación material de la distribución de bienes.

Estos movimientos, que en un inicio tenían un contenido pacifista y ecológico, mostraron el giro de unos valores materiales hacia cuestionamientos al modo de vida y el predominio de la multiculturalidad. De esta manera, dan cuenta de la búsqueda de una política de identidad que implica el reconocimiento de contenidos axiológicos colectivos, 
como respuesta a situaciones de su degradación y desestimación (Honneth, 2006).

Durante las últimas décadas, el concepto de reconocimiento se ha convertido en el núcleo normativo de una multitud de esfuerzos políticos emancipatorios, dado que se vive en una cultura afirmativa en la que el reconocimiento públicamente manifestado posee con frecuencia un carácter meramente retórico (Honneth, 2006), y en la cual los conflictos sociales del siglo XIX y xx pueden entenderse como luchas por el reconocimiento (Ricoeur, 2005).

En el siglo xx, Habermas realiza una exposición sobre el núcleo del Estado de derecho democrático, ya que para él solo la igualdad de condiciones garantiza el respeto o reconocimiento mutuo. En este sentido, la lucha de la moral era entonces un enfrentamiento social, motivado por la necesidad de tener efectos en la comunidad social (Honneth, 1997).

Honneth (1997) en su teoría maneja el concepto de reconocimiento como referencia a la necesidad que tiene el yo de que los demás lo reconozcan y confirmen como sujeto libre y activo, de manera que,

La vida social se cumple bajo el imperativo de un reconocimiento recíproco ya que los sujetos que solo pueden acceder a una autorrealización práctica sin pretender a concebirse a partir de las perspectivas normativas de sus compañeras de interacción, en tanto sus destinatarios sociales. (Honneth, 1997, p. 114)

De acuerdo con esta afirmación, se entiende que el trato igualitario en conjunto con el reconocimiento mutuo pueden ser la base sobre la que se construyan unas ZRC (tal y como se ha buscado durante décadas), porque a partir de esto se puede dar una participación representativa de las comunidades campesinas.

Sin embargo, es importante reconocer que el conflicto armado ha determinado unas dinámicas de represión y criminalización del campesinado, en las que se presenta un genocidio que no se ha reconocido, cuyas víctimas son en su mayoría campesinos de quienes se olvida su condición, precisamente, de víctimas. La dinámica que imprimieron las políticas macroeconómicas desde la década de los ochenta (la apertura neoliberal), debilitó las garantías para la economía campesina. Se perdió el mercado interno, se debilitaron las instituciones, se perdió en autonomía de políticas públicas y se redujo la inversión en el campo, todo lo cual se consolida con el tratado de libre comercio:

Por otra parte, la violencia política, el conflicto armado, las políticas macroeconómicas adversas, generan un desplazamiento, un recrudecimiento y por eso la frontera agrícola se corrió, y la gente empezó a buscar la vida en la Orinoquía, en la Amazonía, en el Pacífico, a abrir selva, y sin garantías, pues lo único que ahí era viable eran los cultivos declarados ilícitos, de ahí toda la explosión de la coca. (Gutiérrez, comunicación personal, 11 de agosto de 2016)

En síntesis, el conflicto armado dejó a los campesinos sin tierra, por ende, sin trabajo y sin forma de sostenerse. Han perdido todo básicamente, sus derechos han sido vulnerados y han tenido que padecer en las ciudades.

De acuerdo con Honneth (1997), el desarrollo social que da con base en conflictos se denomina "lucha de reconocimiento", y se desencadena cada vez que un grupo significativo de individuos madura la conciencia de haber sido objeto de una injusticia. En esta fase se presentan dos factores: el primero de ellos es una adecuada reacción emotiva del interesado, es decir, su conciencia subjetiva de tener derecho a un trato mejor, y el segundo factor es que debe haber un contexto histórico-social favorable que permita la movilización política relevante. La segunda tesis que maneja es la culminación del desarrollo social, representada por una etnicidad en cuyo interior la universalidad del derecho se concilia con el respeto por las múltiples prácticas de vida (Honneth, 1990).

Por tanto, estas tesis presentan la forma en la que el desarrollo social de una comunidad incide en su reconocimiento con autonomía, respeto y condiciones igualitarias, lo que sirve de punto de partida para comprender cómo las zRC podrían cumplir estos dos aspectos y ser el propulsor de reconocimiento y de condiciones igualitarias para las comunidades campesinas.

\section{Formas de reconocimiento}

Honneth (1999) menciona tres formas de reconocimiento en su teoría de justicia de reconocimiento (tabla 1). Estas corresponden al amor, al derecho y 
a la solidaridad, las cuales inciden tanto en el individuo como en el colectivo en el que se desarrolla, en una relación de doble vía por la cual, gracias al reconocimiento que genera, se fortalecen tanto los integrantes como la comunidad en la que se desarrollan.

Honneth (1997) realiza una separación tripartita - basándose en Hegel y su separación entre familia, Estado y sociedad civil- de las formas de reconocimiento que responden al tipo de daño psíquico del individuo. Estas esferas son: la esfera del amor (entendida en un sentido amplio de cuidado y atención); la esfera del derecho; y la esfera del reconocimiento social o de la solidaridad. A cada una de estas esferas le corresponde un tipo de daño: maltrato, violación, tortura y muerte en la esfera del amor; desposesión de derechos, estafa y discriminación en la del derecho; e injuria y estigmatización en la esfera de la solidaridad social. Estos daños quebrantan alguna forma de autorrelación del individuo consigo mismo: la autoconfianza en la primera de las esferas, el autorrespeto en la segunda, y la autoestima en la última (Charles, 1993). La tabla 2 resume esta clasificación.

La justicia debe garantizar las condiciones de la autorrealización, de crecimiento económico, desarrollo sostenible, justicia y equidad social, sin embargo, a fin de superar la brecha que aún existe entre teoría y praxis es preciso preguntarse por los criterios que permitan identificar las mejores medidas para realizar esta tarea, y, por tanto, la discusión sobre justicia y reconocimiento social (Charles, 1993). Luego, el reconocimiento requiere de la adopción de otros elementos que permiten su manifestación como, por ejemplo, la redistribución y la representación, en el propósito de contextualizarlo en el marco del desarrollo igualitario. Así, Fraser (1989) presenta una teoría crítica capaz de

Tabla 1

Formas de reconocimiento

\begin{tabular}{|c|c|c|c|}
\hline Forma & El amor (Liebel) & El derecho (Recht) & La solidaridad (solidaritat) \\
\hline Definición & $\begin{array}{l}\text { Todas las relaciones } \\
\text { primarias entre dos amis- } \\
\text { tades a la relación entre } \\
\text { padre-hijo estriban en } \\
\text { fuertes lazos efectivos. }\end{array}$ & $\begin{array}{l}\text { El sujeto puede saber en qué sentido } \\
\text { es portador de derecho solo en la me- } \\
\text { dida que conoce las obligaciones que } \\
\text { los demás esperan que cumpla. }\end{array}$ & $\begin{array}{l}\text { Valoración social que per- } \\
\text { mite referirse positivamente } \\
\text { a sus cualidades y facultades } \\
\text { concretas. }\end{array}$ \\
\hline $\begin{array}{l}\text { Relación con el } \\
\text { reconocimiento }\end{array}$ & $\begin{array}{l}\text { El reconocimiento debe } \\
\text { tomar el carácter de } \\
\text { aliento efectivo, teniendo } \\
\text { un equilibrio entre la } \\
\text { autonomía y la simbiosis } \\
\text { del otro. }\end{array}$ & $\begin{array}{l}\text { El reconocimiento de la forma de } \\
\text { socialización del individuo a vivir sin } \\
\text { derechos individuales significa para el } \\
\text { miembro de la sociedad no tener nin- } \\
\text { guna oportunidad para la formación } \\
\text { de autoestima. }\end{array}$ & $\begin{array}{l}\text { El reconocimiento depende del } \\
\text { horizonte de los ideales y metas } \\
\text { colectivas, este a su vez debe } \\
\text { ser amplio para integrar las } \\
\text { diferentes aptitudes de cada uno } \\
\text { a la vida social. }\end{array}$ \\
\hline
\end{tabular}

Nota. Tomado de Honneth, A. (1997). La lucha por el reconocimiento. Por una gramática moral de los conflictos sociales. Barcelona: Crítica, p. 37.

Tabla 2

Patrones de reconocimiento intersubjetivo

\begin{tabular}{|c|c|c|c|}
\hline Modelos de reconocimiento & Dedicación emocional & Atención cognitiva & Valoración social \\
\hline Dimensión de personalidad & $\begin{array}{l}\text { Naturaleza de la necesidad } \\
\text { del afecto }\end{array}$ & Responsabilidad moral & Casualidades, capacidades \\
\hline Formas de reconocimiento & Relaciones primarias & Relaciones de derecho & Comunidad de valor \\
\hline Potencial de desarrollo & & Generación, materialización & Individualidad, Igualación \\
\hline Autorrelación practica & Autoconfianza & Autorespeto & Autoestima \\
\hline Formas de menosprecio & $\begin{array}{l}\text { Asesinato, maltrato psíquico } \\
\text { y físico, violación, tortura }\end{array}$ & $\begin{array}{l}\text { Desposesión de derechos, } \\
\text { exclusión, estafa }\end{array}$ & $\begin{array}{l}\text { Indignación, injuria, } \\
\text { estigmatización. }\end{array}$ \\
\hline
\end{tabular}

Nota. Tomado de Honneth, A. (1997, p 159), complementado con Honneth (2006). 
integrar las reivindicaciones actuales presentes en los movimientos sociales, y con esto pone de manifiesto la injusticia y su posible reparación, sin perder de vista en ningún momento el correlato social fáctico de la teoría; menciona que las reivindicaciones de justicia social se dividen en dos tipos: el primero da a conocer una redistribución más justa de los recursos y la riqueza al brindar una solución para los problemas de desigualdad y la injusticia que se evidencian en la sociedad; el segundo habla de una política de reconocimiento en la que se acepte la diferencia y se reconozcan las diferentes identidades que en la actualidad - con los procesos de globalización- se convierten en la problemática de la desigualdad basada en la redistribución de los recursos por un falsa lucha de estatus en la sociedad (Fraser, 2008).

Fraser y Honneth (2006) realizó una revisión de los límites sobre los procedimientos de decisión que se imponen a un grupo de individuos para participar en las cuestiones que les atañen, en un marco político-ordinario, esto es, territorial-estatal o, dicho de otro modo, al interior de las fronteras de los Estados en los que se encuentran instalados. Esto implicaría también un análisis de la exclusión de inmensos grupos campesinos que se ven atropellados por instituciones y prácticas depredadoras globales, exclusión operada por la delimitación territorial-estatal de aplicación de la justicia, la cual tiene como efecto que tales atropellos se perpetúen en la impunidad ante la inexistencia de instituciones formales que puedan sancionarlos y prevenirlos (Fraser y Honneth, 2006). Desde esta perspectiva se puede observar cómo la falta de apropiación del territorio excluye a los grupos campesinos y los margina de sus derechos:

Las líneas de tiempo están directamente relacionadas, porque si no hay campesinos en la periferia, con la necesidad de sobrevivir, la dinámica de los cultivos ilícitos no habría sido tan fuerte. Los campesinos no tenían otra opción, porque habían unos productos que en el marco adverso de la economía, donde no hay garantías, pues los productos que son viables son los de las personas que están cerca de las ciudades, en los Andes cerca de los centros urbanos, de resto usted se aleja kilómetros y se le va volviendo inviable cualquier producto entonces en la práctica la coca, la mariguana, la amapola, son una válvula de escape a esa situación porque no hay otra alternativa, por eso el tema de la sustitución que está también en los acuerdos que es fundamental sustituir pero desde un enfoque fundamental, donde se recupera la viabilidad de la economía campesina con garantía, con economía pública, con un mercado interno que garantice para la población campesina, pues si eso no se hace y se quiere imponer, hace que una población campesina se desplace a la ciudad a mendigar, a volverse delincuente pero de resto no hay posibilidad alguna, en conclusión los ha afectado en despojo de tierras, calculadas por lo menos en ocho millones de hectáreas. (Testimonio líder campesino)

Fraser y Honneth (2006) denomina redistribución y reconocimiento "representación" y menciona que el problema del reconocimiento en cuanto identidad determina un límite en las soluciones de tipo afirmativo, dado que exige a estos grupos reflexionar y replantear los elementos que los constituyen (Fraser y Honneth, 2006). Así, evidenciamos que la organización de los campesinos en los territorios que han sufrido el azote de la violencia en Colombia se realizó con el fin de reflexionar y replantear lo que ha sucedido. Por esto mismo, la creación de asociaciones, el agrupamiento y la realización de reuniones que propicien consensos en el marco de la creación de las zRC genera el entorno apropiado para que los elementos de redistribución, reconocimiento y representación se materialicen y se hagan evidentes.

El proyecto teórico de Fraser y Honneth (2006) consiste en recuperar la discusión de las exigencias de carácter cultural a partir de la transformación del estatus de participación política y validación de estas en los espacios públicos. La categoría de representación política permite a Fraser identificar otra forma de injusticia respecto a las sociedades contemporáneas denominada "representación fallida", la cual se manifiesta de dos maneras: la primera es la injusticia política (ordinaria dentro de un Estado moderno), y la segunda la injusticia de desmarque que rompe con los límites del Estado nacional moderno (Fraser, 1989).

La propuesta de Fraser sostiene un modelo crítico democrático frente a la forma en la que la justicia social activa la dimensión epistémica del "quién" con respecto a la esfera política, el cual solo tiene la posibilidad de realizarse mediante la "transformación de una lógica de razón de Estado a una lógica de razón pública” (Fraser y Honneth, 2006). 
Las condiciones de anormalidad política y las exigencias analíticas en relación con el marco de la justicia implican que la nación tome un sentido transnacional, según el cual la idea de una esfera pública transnacional solo podrá contar con validez bajo una condición de inclusión y paridad al participar, seguida de la eficiencia política de la transformación del poder comunicativo en leyes vinculares del poder. Ante esto se encuentra que se propone una estrategia política con el fin de integrar las dos demandas, es decir, el dilema de redistribución-reconocimiento de la injusticia socioeconómica, tal como se muestra en la tabla 3.

La tabla 3 permite visualizar cómo las corrientes políticas afectan y provocan de manera diferente la redistribución y el reconocimiento de las comunidades, pese a lo cual estos dos elementos son fundamentales en el desarrollo de estas.

Se concluye que la redistribución y el reconocimiento provocan la representación de las comunidades, lo cual se evidencia en diferentes planos como, por ejemplo, el social y el económico, lo que conduce a revisar la evolución de las zRC.

\section{Consideraciones acerca de las ZRC}

Se considera que las zonas de reserva campesina han sido el único referente de desarrollo legal de los derechos del campesinado, o por lo menos uno de los más importantes. Por supuesto, se cuenta con disposiciones normativas frente a la formalización de la propiedad familiar, pero hay una fuerte limitación en la concepción del campesinado como un sujeto político y deliberativo de las decisiones importantes de este país.

El asunto con el campesinado es reconocerlo como actor decisorio de la política ambiental, económica, tributaria, minera y alimentaria de este país, y no llegar únicamente a tratar de establecer condiciones específicas; es decir, son necesarias, pero no son la única forma. En este sentido, las zonas de reserva campesina son una expresión que permite al campesinado proyectar una plataforma de acción política a nivel nacional mediante la cual sea un agente deliberativo con capacidad de incidir en el ordenamiento del territorio, así como en la ejecución de decisiones políticas y con el reconocimiento - si se quiere- en el ejercicio de la territorialidad en determinados lugares, de manera que se abran espacios para su participación. Por supuesto, tendrá esto que ser complementario a otro tipo de mecanismos a través de los consejos municipales de desarrollo rural, con el propósito de que activen algunas formas de participación o reconozcan nuevas, revitalicen la figura de las juntas de acción comunal, las fortalezcan más, las empoderen y reconozcan expresiones organizativas del campesinado como parte de esa manifestación colectiva del ser campesino; es decir, si se quiere buscar a los campesinos no hay que inventarse nuevas formas de políticas organizativas, se deben reconocer las existentes, como, por ejemplo, los resguardos y los

Tabla 3

Estrategia política afirmación vs. transformación

\begin{tabular}{ccc}
\hline Afirmación & Redistribución & Transformación \\
\hline $\begin{array}{c}\text { Estado de bienestar: Liberal } \\
\text { Reasignaciones de la superficie de los productos existentes, } \\
\text { apoyando la diferenciación entre los grupos que pueden } \\
\text { generar reconocimiento }\end{array}$ & $\begin{array}{c}\text { Profunda reestructuración de las relación de producción, } \\
\text { eliminando las diferencias entre los grupos que pueden } \\
\text { ayudar a aliviar algunas formas de no reconocimiento. }\end{array}$ \\
\hline $\begin{array}{c}\text { Multiculturalismo central } \\
\text { Reasignaciones superficiales de respeto por las identidades } \\
\text { de grupo: apoya la diferenciación entre los grupos. }\end{array}$ & $\begin{array}{c}\text { Profunda reestructuración de las relaciones del reconoci- } \\
\text { miento, desestabiliza diferencia entre los grupos. }\end{array}$ \\
\hline
\end{tabular}

Nota. Tomado de Fraser y Honneth (2006, p. 149). 
cabildos (en las que la relación entre cabildo y resguardo es importante) $y$, de esta manera, estar en capacidad de reconocer como idea propia una manera de proceder, de deliberar las representaciones tradicionales, pero también de decidir cómo reestructurar o reinstitucionalizar las normas internas para el ejercicio de la democracia.

Las zonas de reserva campesina pueden ser una gran herramienta para reconocer al campesino. Se empieza por impulsar el desarrollo económico, mejorar las condiciones y la calidad de vida del campesinado, y asegurar así que ellos puedan acceder a factores productivos y sociales que contribuyan a la superación de la pobreza extrema rural, en la que actualmente se encuentran. De esta forma, les permite avanzar hacia estadios superiores de desarrollo con la generación de cooperación y modernización de las zonas rurales y una vida digna de la familia campesina (en consideración a la efectividad de los derecho sociales, económicos y culturales del campesinado), así como una participación en las instancias de planificación y decisión regionales y las características de las modalidades de producción.

Las zonas de reserva campesina tienen una trayectoria desde finales de la década de los ochenta y un reconocimiento legal desde la de los noventa, de modo que son ya seis las que están legalmente constituidas. Son procesos que no tienen reversa en lo organizativo - claro, presentan muchos problemas y muchas particularidades-, pero son la figura que va a jugar un papel muy importante en la solución del problema de acceso a tierras, de su formalización y de la presencia efectiva del Estado; es la única fórmula que existe en toda la legislación para los territorios campesinos.

\section{La identidad del campesino en Colombia}

En términos de identidad, se considera que la población campesina tiene una alta identidad política y social, lo cual es un asunto que depende de los territorios. Esta identidad, por supuesto, puede construir lógicas organizacionales de carácter nacional bajo un mismo discurso, pero esas formas de identidad política y social no son solo una, sino que se van a caracterizar como diversas, de manera que le permiten al campesinado construir un modelo identitario que exprese lo que hay en el territorio, lo que es la gente, lo que la gente vive y quiere decir y ha dicho y, al lo que muchas veces, no se le ha prestado atención.

De modo que ya tienen una identidad que han forjado ellos, pero esta no ha sido reconocida por el Estado por medio de la Constitución. Por ejemplo, ellos han formado una unidad para luchar por sus derechos. Así, pues, podemos considerar que la población campesina tiene una identidad propia autoconstruida y que esta población es excluida. Es por esto que nos interesa estudiar la economía campesina como base para identificar la identidad de los campesinos en Colombia.

La economía campesina surge en la década de lo sesenta del siglo $\mathrm{xx}$ mediante una corriente de investigación y pensamiento en el tema agrario al profundizar en la gestión de las unidades de explotación familiar, cuyo exponente principal es Chayanov (1925). Los procesos de consolidación de la economía campesina fortalecen territorios campesinos y el proyecto político y cultural de esta población, lo cual hace que las comunidades campesinas desarrollen proyectos que deben tener garantía de los derechos económicos, culturales, sociales y ambientales en territorios específicos y bajo su lógica sociocultural (Gilmore y Harrison, 1948).

En su obra La organización de la unidad económica (1925), Chayanov establece tres secciones. En la primera, determina las categorías fundamentales: la familia campesina y el balance trabajo-consumo, base de su racionalidad económica; en la segunda delimita las características de la unidad de explotación a nivel organizativo; y, por último, finaliza con la mención de las consecuencias que para el sistema económico se derivan de la existencia de este tipo de explotaciones y aspectos de su dinámica de inserción (Chayanov, 1986). Este autor construye sus cimientos teóricos diferentes a los característicos del pensamiento marxista y la concepción derivada de Marx.

Según Chayanov (1986), los efectos de la economía clásica o de los neoclásicos no son aplicables a una economía que está basada en el trabajo familiar; la base de su construcción teórica es que esta unidad familiar pueda conformarse por hijos, nietos e incluso miembros adoptados, convirtiéndose estos en el sujeto económico que emplea su fuerza de trabajo en una serie de actividades y le da prioridad al cultivo del suelo (Gilmore y Harrison, 1948).

La economía campesina es una forma de producción familiar que utiliza productivamente el 
consumo de la fuerza de trabajo doméstica y de los recursos naturales, sociales y financieros, con el fin de garantizar la subsistencia de la unidad familiar. El objetivo principal de esta es el bienestar de las familias y, dentro de la utilidad marginal, se imponen solo mecanismos de equilibrio entre los factores internos (Clark, 1969).

En la figura 1 aparece el esquema de la distribución de trabajo e ingresos de la unidad doméstica, en la que el autor pone de relieve las fuentes de ingreso de la unidad doméstica y, de forma muy general, la ilustración describe los momentos del enfoque chayanoviano concernientes a la base empírica. Chayanov señala al respecto:

La actividad económica del trabajo difiere de cualquier otra actividad en la que la cantidad de valores que se hacen disponibles al campesino concuerda con la cantidad de trabajo físico que él ha gastado, donde a mayor cantidad de trabajo realizado por un hombre en un intervalo de tiempo definido, mayor será para el sujeto de laboriosidad de las últimas unidades de trabajo invertido. (Chayanov, 1986, p. 81)
El punto de equilibrio es el grado de autoexplotación de la fuerza de trabajo familiar que el campesino considera óptimo, y los dos elementos claves del balance son la necesidad de consumo e intensidad y del trabajo, afectados por la composición de la actividad de la fuerza del trabajo que determina, por su parte, el volumen de la actividad económica (Chayanov, 1986).

El balance del consumo-trabajo es el principal regulador de la actividad de la unidad de explotación familiar. Por su parte, la determinación del ingreso bruto se obtiene al deducir los gastos necesarios de mantenimiento, a fin de obtener también el producto definitivo, fruto del trabajo familiar.

La gran migración del campo y el crecimiento desordenado de las grandes ciudades requieren que el país establezca la prioridad de darle al sector rural y agrario, en el marco de las políticas macroeconómicas y sociales, la alimentación de la población urbana como estrategia de desarrollo y bienestar. La existencia de una economía campesina lleva aparejada el autoconsumo (no de acumulación) y la restricción de la circulación de la mercancía (Biegeleisen, 1916).

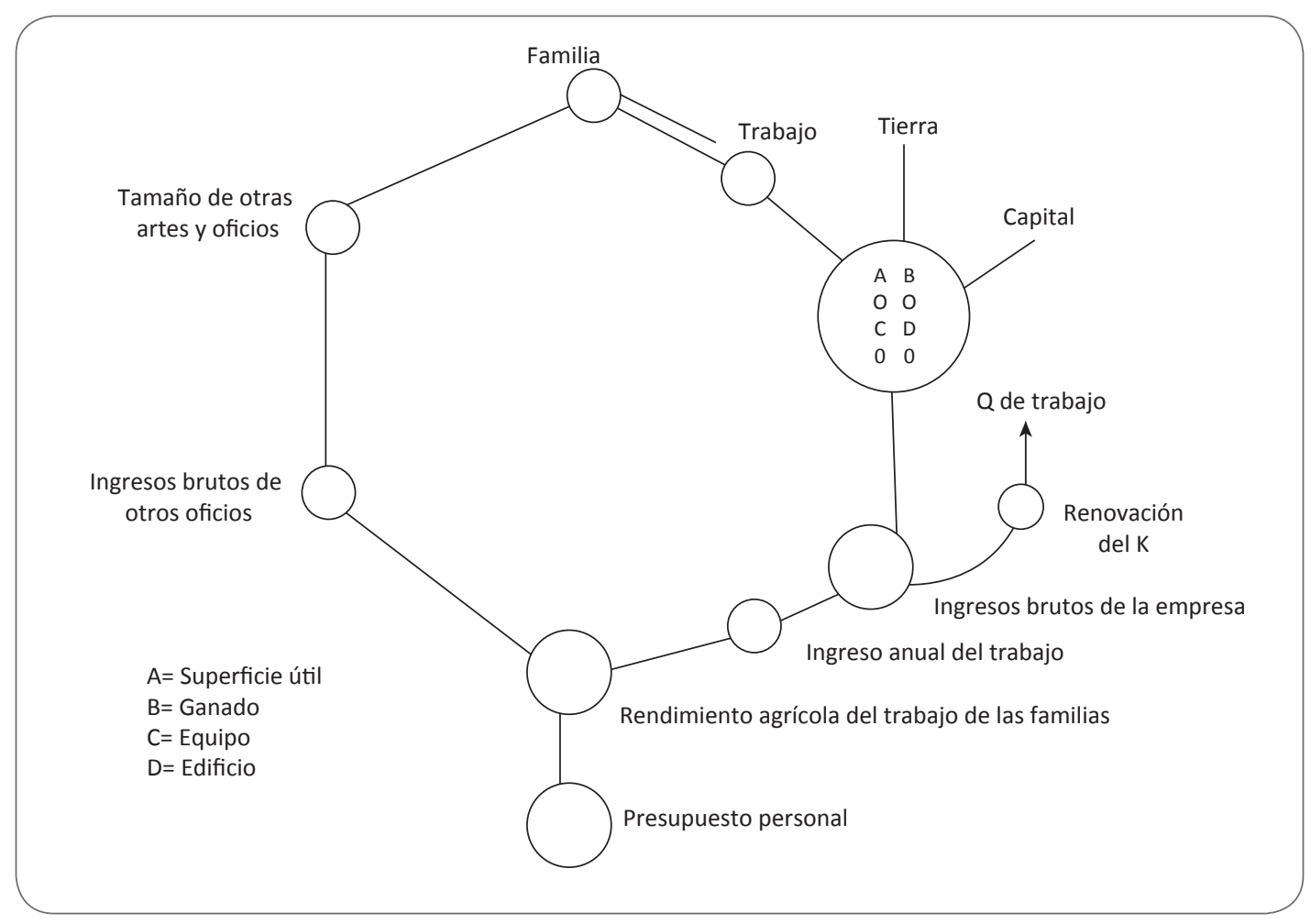

Figura 1. Esquema de la distribución de trabajo e ingresos de la unidad doméstica. Tomado de Chayanov (1986, p. 81). 
Así, la economía campesina corresponde a un sistema cíclico en el cual la familia y el terreno son los elementos principales de producción, y en el que la primera es la mano de obra y quien aporta el capital para que la segunda pueda, como unidad productiva, arrojar en el tiempo los frutos del esfuerzo y los recursos colocados. Las variaciones son mínimas y el conjunto como tal genera y afecta la economía tanto de la familia como de cada uno de los individuos que la conforman.

\section{Relación existente entre la zona de reserva campesina y el reconocimiento social del individuo}

Respecto a los derechos de la población campesina, el Estado ya tiene obligaciones para con el campesinado, por las que los derechos son un proceso de reivindicación humana que tiene un punto muy relevante para el estudio de la dogmática jurídica en su positivización en el derecho estatal. Sin embargo, el análisis de los derechos humanos no puede solo restringirse a la dogmática estatal, pues en este sentido se considera importante que el Estado colombiano pueda adoptar de forma explícita derechos para el campesinado, de manera diferenciada y taxativa; por el contrario, a fin de que permita un reconocimiento cultural del campesinado en el derecho como producto cultural el análisis tiene que "campesinarse", porque si se tiene un derecho pensado para un reino industrial de producción de la vida no se va a entender qué pasa en el campo. En este sentido, se debe empezar por comprender con relación a los derechos que el Estado debe entrar a garantizar esas expresiones subalternas que tiene el mundo, en las cuales reivindica formas de la dignidad que se traducen en derechos, aun cuando el Estado no es capaz - no quiere o no puede- reconocerlos de manera efectiva o de manera explícita. Interpretar la cláusula de derechos innominados de la Constitución permite simplemente entender que los derechos no tienen que pensarse como un catálogo internominado o, en la lógica de una anunciación de los derechos que debería reconocerle el Estado al campesinado en un marco muy decimonónico como el de la Revolución francesa o la Carta de Derechos, sino que debe entenderse que el campesinado produce derecho y regula sus formas de vivir. Así, entonces, el Estado debe asumir unas obligaciones no en términos solo de un listado taxativo en el que la economía campesina es un muy buen ejercicio de sistematización, sino que debe reconocer que el campesinado es un sujeto capaz de regular las relaciones, capaz de mandar en su territorio y capaz de administrar ambientalmente la vida en el territorio en el que se encuentra. De esta forma, la principal reivindicación del campesinado es que se reconozca como promotor de los derechos, de manera que, si fuera necesario escoger una obligación, se debe escoger la obligación a reconocer al campesinado como un agente y un actor del territorio, y no como un mero accesorio. Esto en razón a que no es un sujeto pasivo del derecho al cual se le concedan prerrogativas, sino que es un sujeto activo, construye formas de dignidad que administra y produce derecho, de modo que la obligación del Estado es reconocer ese carácter dinámico.

Por tanto, el rol del Estado debe ser comprometerse y, sobre todo, cumplir con el campesinado al garantizarle un trato digno, una identidad y derechos campesinos, así como al ser un promotor del desarrollo rural y agropecuario, y como regulador de los valores, de distribución igualitaria de la tierra y de los ingresos relacionados con la actividad. Lo anterior dado que el papel del Estado hasta el momento ha sido mínimo a pesar de disponer de varios instrumentos para lograr estos objetivos, sin dejar de lado que debe crear leyes eficientes y eficaces para que Colombia crezca y genera desarrollo tanto en el campo como en la ciudad.

El territorio, tal y como se ha entendido, ha jugado un papel primordial en el desarrollo de las labores agrícolas, propias del modo de vida y de la idiosincrasia del campesino colombiano. Por esto, la figura de las zRC tiene que ver con su reconocimiento social, tanto a nivel de población como de elemento cultural de trascendencia histórica, con repercusiones en el presente. En razón a lo anterior, se profundizará en las perspectivas de las ZRC a continuación.

\section{Perspectivas dispuestas para las zonas de reservas campesinas en función del plan de ordenamiento territorial}

Hasta el momento, se ha caracterizado la figura de las ZRC desde las definiciones legales y las reglamentaciones que hacen operativa la figura. Sin embargo, este esfuerzo sería insuficiente si no se ilustra la historia de la creación de estas zonas. A continuación, se presenta una breve reseña de los 
orígenes de la figura, la cual es el resultado de las luchas campesinas que se plasman en movilizaciones y protestas en busca de la titulación de las tierras, la seguridad y la atención del Estado para la protección de sus derechos.

La figura de zonas de reserva campesina es una reivindicación que nació de algunas comunidades campesinas organizadas, la cual se fue complejizando hasta adquirir el carácter de ley (Ortiz y Pérez, 2004). Según Mondragón (2003), la práctica de la reserva campesina antecede a la idea de la formalización de esta en la legislación agraria, pues nace de la lucha de los campesinos por detener la expansión del latifundio sobre sus propiedades. Este autor, que ha estudiado los procesos organizativos de los campesinos en Colombia, afirma que esta figura materializa la aspiración de los campesinos de desarrollar su economía y participar decisiva y adecuadamente en la economía nacional. Considera que en las luchas de siglo xx de los campesinos estos reivindican la tierra no solo desde una visión individual, sino dentro de las dinámicas comerciales y regionales de gestión campesina del territorio.

De acuerdo con Fajardo (2002), los antecedentes de las ZRC pueden rastrearse desde 1985 en la zona de colonización que se extiende a lo largo de las márgenes de los ríos Duda, Losada, Guayabero y Guaviare, en el suroccidente del Meta y el noroccidente del Guaviare, en donde las economías locales se fundamentaban desde varios años atrás en el cultivo de coca.

Debido al decaimiento de esta economía, los colonos vieron agudizadas sus condiciones de pobreza y se movilizaron para reclamar del Estado la ausencia de inversiones sociales. Una de las reivindicaciones era la titulación de las tierras que habían trabajado, las cuales estaban dentro del Parque Natural de La Serranía de la Macarena. Esta solicitud implicaba el realineamiento de este y la zonificación del área. Según Fajardo, fueron los campesinos de la cuenca del río Duda quienes bajo el propósito de avanzar en el ordenamiento y la estabilización de este territorio le propusieron al Incora que se les titulara la tierra en medianas extensiones a cambio de su compromiso de preservar los bosques y demás recursos naturales aún existentes. Es esta la idea que subyace las definiciones que se plasmaron luego en la legislación colombiana como zRC.

Sin embargo, el proceso de concreción de esta política pública no ha sido sencillo y, por el contrario, se ha visto marcado por movilizaciones por parte de las organizaciones sociales y de negociaciones con el sector político y legislativo del país. Es necesario recordar que esta figura está contenida en la Ley 160, la cual también determina el mercado asistido de la tierra como el único mecanismo de distribución de esta en Colombia.

\section{Actuación de la democracia en torno a las zonas de reservas campesinas}

A pesar de la pertinencia de las zRC para la solución de muchas de las problemáticas agrarias del país, esta figura no fue implementada de inmediato. Son las protestas de las comunidades de las zonas cocaleras de Putumayo, Caquetá, Cauca, Sur de Bolívar y Guaviare —desarrolladas en 1996 a raíz de los controles a los insumos para el procesamiento de hoja de coca, la persecución y estigmatización de los productores y las fumigaciones que afectaban tanto los cultivos de uso ilícito como los de subsistencia-, las que presionaron la reglamentación de la figura y la declaración de las primeras zRc. Fue este proceso social el que conllevó a la promulgación del Decreto 1777 (mencionado en el apartado anterior), en el marco de las reivindicaciones de los campesinos relacionadas con el acceso a tierras y asistencia técnica como un camino a la búsqueda de alternativas para la sustitución de los cultivos de uso ilícito.

Estas movilizaciones también incluyeron en su pliego de negociaciones la creación de las primeras ZrC: la de Guaviare (Tomachipán, en San José del Guaviare y Calamar), Caquetá (El Pato, en San Vicente del Caguán) y Bolívar (Morales y Arenal). En 1997 la Junta Directiva del Incora constituyó la primera zRC en parte de los municipios de San José, El Retorno y Calamar. Luego, en este mismo año fue constituida la segunda ZRC en las localidades del Pato Balsillas.

Sin embargo, su constitución formal no era suficiente para hacer concreta la idea de la zRC. Después de la creación de las primeras zonas se hizo evidente que el Gobierno no contaba con los insumos técnicos y metodológicos para cumplir con lo que la figura jurídica se proponía. Por esta razón, en octubre de 1998, se inicia la ejecución de un proyecto experimental con financiación del Banco Mundial denominado "Proyecto Piloto de Zonas de Reserva Campesina (PPZRC)". Este se proponía diseñar una metodología replicable para la organización y el funcionamiento de las zRC. Se 
desarrolló en tres zonas piloto: Pato Balsillas en el departamento de Caquetá, la conformada por los municipios de San José, El Retorno y Calamar en el departamento de Guaviare, y la zRC del municipio de Cabrera, conformada en el 2000. Este proyecto, que culminó el 31 de diciembre del 2003, asumió el reto de desarrollar en estas zonas mecanismos de aproximación y concertación con la comunidad y coordinación con la institucionalidad publica dentro de un modelo novedoso de gestión de desarrollo territorial y local.

El inicio del Gobierno del presidente Juan Manuel Santos coincide con el I Encuentro Nacional de Zonas de Reserva Campesina, realizado en Barrancabermeja en agosto del 2010. En este evento, que contó con la participación del Gerente del Incoder y de voceros del Ministerio de Agricultura, confluyeron diferentes asociaciones campesinas de las ZRC ya constituidas y aquellas que están buscando la creación de estas, además de académicos, investigadores y diversas ONG nacionales e internacionales.

Este evento se diseñó como un espacio de encuentro y articulación de las organizaciones relacionadas con la figura, así como para la socialización de esta ante otras organizaciones interesadasen articular sus procesos a la creación de ZRC.

Estas organizaciones definen la figura como un mecanismo apropiado para el desarrollo rural, el ordenamiento y la planeación territorial que permite construir desde la región alternativas para el desarrollo integral de las comunidades campesinas.

En el evento se dio visibilidad a las problemáticas que el sector campesino enfrenta y que amenazan los territorios que ellos afirman defender. En este sentido, se denunció la desarticulación de los procesos organizativos en algunas regiones debido a las amenazas de los grupos paramilitares y el temor que existe en los campesinos por las represalias que puede haber frente los procesos organizativos. También se denunció la situación de extrema pobreza que caracteriza a los territorios campesinos y los impactos negativos para los pobladores rurales de las políticas de erradicación forzada de los cultivos de uso ilícito, como, por ejemplo, las fumigaciones.

El proyecto de Ley general de tierras, reforma agraria y desarrollo rural integral presentado por el Movimiento Campesino, por medio de la Mesa Nacional de Unidad Agraria (MUA), también contiene un capítulo especial sobre las zRC. Presenta algunas disposiciones relacionas con la definición de la figura, sus finalidades, los procesos de constitución, el acceso a créditos y los ámbitos de aplicación. En este proyecto, la figura no se desarrolla en profundidad, pero contiene elementos importantes en relación con los territorios indígenas y las comunidades afrocolombianas, el presupuesto para la consolidación de las zRC y el tema de la UAF.

\section{Conclusiones}

Una vez se analizan los antecedentes históricos y el marco jurídico de las zonas de reserva campesina se concluye que en su planteamiento e implementación hubo elementos que se remontan a los inicios del siglo $\mathrm{xx}$, enmarcados por la tenencia de las tierras que, a su vez, se vio alterada por circunstancias particulares de las diferentes épocas. Sin embargo, sin lugar a duda el principal evento que influyó fue el conflicto armado, el cual provocó no solo consecuencias en cuanto a la expropiación, sino que alteró el orden social del campesinado al hacerlo víctima de desplazamiento e involucrarlo en actividades de cultivos ilícitos que le permitieran sobrevivir. Este contexto, además del papel del Gobierno en función de proteger y salvaguardar la labor agrícola del país, llevó a planear y desarrollar la estrategia de las zonas de reserva campesina, la cual se ha ido implementando de forma progresiva en diferentes regiones del país.

En cuanto a la postura de los campesinos sobre la manera como se reconocen y se construyen sus identidades en relación con el territorio y con la sociedad, se encontró que el campesinado mantiene una identidad de acuerdo con su modo de vida y con su labor agrícola, y siente que se ha estigmatizado un poco dicha identidad por su cercanía con los actores armados del conflicto en Colombia. Ante lo cual consideran que es importante rescatar la imagen que de ellos se tenía hace algunos años de productores y trabajadores del campo. Por otra parte, consideran que son parte de la sociedad como una comunidad perfectamente diferenciada, aun cuando heterogénea en su idiosincrasia, por la forma de abordar las situaciones y el manejo agrícola, lo cual los hace altamente diversos. En esto tiene mucho que ver la región geográfica en la que se encuentran y, por supuesto, la posibilidad de tener jurisdicción sobre las tierras en las que habitan y trabajan. Por ende, consideran que efectivamente su relación con el territorio hace parte de la identidad que tienen, así como con la sociedad en la que se desenvuelven. 
Con base también en lo anterior, se encontró que existe una marcada relación entre la zona de reserva campesina y el reconocimiento social del individuo campesino, ya que estas zonas le brindan sentido de pertenencia y la posibilidad de dar lo mejor de sí en el trabajo de la tierra. Al mismo tiempo, este reconocimiento podría hacer que el campesino se sienta apoyado de alguna manera por el Estado mediante sus políticas (aun cuando en lo económico no son, a su parecer, las mejores, por lo menos ahora se sienten escuchados). Las zRc han permitido, a su vez, que el campesinado se sienta con voz y posibilidades de ser escuchado en la toma de decisiones en temas relacionados con el campo, el medio ambiente y los desarrollos socioculturales de sus regiones.

Finalmente, se concluye que las zonas de reserva campesina se pueden considerar como una estrategia de reconocimiento social para el campesinado colombiano, ya que han llegado a ser - en los diferentes sectores del país en los que se han establecido, y en aquellos sectores en donde están por establecerse un mecanismo de asociación del gremio campesino - la forma de ser actores activos dentro de los procesos de decisiones que les atañen como comunidad.

\section{Referencias}

ACNUR. (2015, diciembre). Agencia de la onu para refugiados. Recuperado de http://www.acnur.org/donde-trabaja/america/colombia/

ACNUr. (2016). El informe anual de ACNUR. Tendencias globales sobre refugiados y desplazamiento. Recuperado de http://www.acnur.org/recursos/estadisticas/

Biegeleisen, L. W. (1916). Rozwoi gospodarczy nowoczesnej wsipolskeij [El desarrollo económico del campo en Polonia moderna]. Cracovia: NKK.

Charles, T. (1993). El multiculturalismo y la política del reconocimiento. Mexico: Fondo de Cultura Económica.

Chayanov, A. (1925). Peasant farm organization. En D. Thorner, B. Kerblay y R. E. F. Smith (Eds.), A.V. Chayanov on the theory of peasant economy (pp. 29270). Illinois: The American Economic Association. (Primera impresión, 1966).

Chayanov, A. (1986). The Theory of Peasant Economy, ed. and introd. By Daniel Thorner, Basile Kerblay and R. E. F. Smith, Homewood, Ill.

Chayanov, M. H. (1975). Chayanov and the economics of the Russian peasantry. Journal of Peasant Stuides.
Departamento Administrativo Nacional de Estadística (DANE). (2016). Tercer censo nacional agropecuario. Hay campo para todos. Recuperado de http://www. dane.gov.co/index.php/Censo-Nacional-Agropecuario-2014

Fajardo-Herrera, K. N. (2015). Las zonas de reserva campesina como estrategia de reconocimiento social. Trabajo final de investigación presentado como requisito parcial para optar al título de profesional en finanzas y comercio internacional. (tesis de pregrado). Bogotá: Universidad de La Salle.

Fajardo, D. (2002). Para sembrar la paz, hay que aflojar la tierra: comunidades, tierras y territorios en la construcción de un país. Universidad Nacional de Colombia.

Fraser, N. (1989). Unruly practices, discourse and gender in contemporary social theories. Minneapolis: Universidad de Minesota.

Fraser, N. (2008). Escalas de justicia. Herder.

Fraser, N. y Honneth, A. (2006). ¿Redistribución o reconocimiento? Madrid: Morata.

Fuerte, A. y Tacha, V. (2015). Legislando contra el campesinado. Revista Semillas. Recuperado de: http://semillas.org.co/es/revista/legislando-contra-el-campesinado

Gilmore, R. L. y Harrison, J. P. (1948). Juan Bernardo Elbersand: the Introduction of Steam Navigation on the Magdalena River. Hispanic American Historical Review 28(3), 325-359.

Honneth, A. (1990). Teoría critica: la teoría social. Madrid: Alianza.

Honneth, A. (1997). La lucha por el reconocimiento. Por una gramática moral de los conflictos sociales. Barcelona: Crítica.

Honneth, A. (1999). Entre Aristóteles y Kant: esbozo de una moral del reconocimiento. Logos: Anales del Seminario de Metafísica, 32, 17-38.

Honneth, A. (2006). El reconocimiento como ideología. Isegoría, 35, 129-150.

Ministerio de Agricultura y Desarrollo Rural. (2013). Propuesta de estructura orgánica básica del Ministerio de Agricultura y Desarrollo Rural. Usaid-Colombia.

Mondragón, H. (2003). Expersiones del campesinado.Recuperado de https://vertov14.files.wordpress.com/ 2012/01/expresiones-del-campesinado-hector-mondragon.pdf

Morales, J. C. (2015). La importancia de reconocer los derechos humanos de la población campesina. Revista Semillas, 61/62. Recuperado de: http://semillas.org. co/es/revista/la-importancia-de-reconocer-los-derechos-humanos-de-la-poblaci 
Ortiz, E y Pérez, M. E. (2004). Zonas de Reserva Campesina: aprendizaje e innovación para el Desarrollo Rural. Bogotá: Universidad Javeriana.

Osejo, A. (2013). Zona de reserva campesina: política pública y estrategia para la defensa de territorios campesinos, aportes para su reglamentación y aplicación. Recuperado de http://www.indepaz.org.co/ wp-content/uploads/2013/04/Zona_de_Reserva_ Campesina_Politica_publica_y_estrategia_para_ la_defensa_de_territorios_campesinos.pdf
Ricoeur, P. (2005). Caminos del reconocimiento: tres estudios. Madrid: Trotta.

Rural, M. D. (2007). Desplazamiento, DH, DIH y reconciliación. Bogotá: Conpes. 